\section{Pityriasis Lichenoides}

Q.-What is the cause of acute pityriasis lichenoides, and how should it be treated?

A.-The cause of pityriasis lichenoides is not known and there is no effective treatment. It clears spontaneously, but may last for months or years before this happens. General ultra-violet irradiation seems sometimes to favour recovery.

\section{Behçet's Ulcers}

Q.-What treatment is there for Behçet's ulcers of the vagina in a woman aged 30 who has had three normal confinements? Are recurrent monilial infections associated with this condition? Are oral contraceptives contraindicated?

A.-Behçet's syndrome consists of periodic ulceration of the mouth, often associated with conjunctivitis and with cyclical ulceration of the vagina, vulva, and anus. Genital ulceration may occur in the absence of buccal lesions, and these ulcers are then sometimes called Lipschutz ulcers. The origin of the condition is moscure. The Bacillus crassus, a normal inhabitant of the vagina, has been incriminated, but the evidence for this is doubtful. There is no known association with monilial vaginitis. The most likely origin is allergic.

The condition tends to disappear during pregnancy and lactation, and for this reason alone an oral contraceptive, which produces a state of pseudopregnancy, would seem to be worth a trial. Local applications are, on the whole, disappointing in their effect. An ointment or cream containing cortisone appears to be the most successful in dealing with what is often a difficult and intractable condition.

\section{Mongolism on Both Sides}

Q.-What are the chances of a mongol child being born to a young couple of whom the wife's grandmother and the husband's mother had a mongol child?

A. - With this family history it would be most desirable to have chromosome investigations done on both husband and wife before advising on the risks of mongolism in their children.

\section{Painful Calves in Children}

Q.- $A$ healthy girl aged 8 has had recurrent spells of aching in the calves, mostly at night, intermittently for four years. Aspirin gives some relief. Clinical examination shows no abnormality. What could be the cause?

A.-Pain in the calf muscles is an occasional symptom in young children. It is usually intermittent, worse at night, and is unassociated with any constitutional illness. As in this case, full medical examination serves to exclude anaemia, coarctation of the aorta, orthopaedic conditions, or a peripheral neuritis. Trichinosis is an uncommon cause of muscle tenderness and it might be worth having an $x$-ray to exclude calcified cysts.
Local treatment is often unhelpful. Calcium gluconate is sometimes prescribed, and I have known it to be effective on two occasions even when the serum calcium was normal. I have no record whether the ionized calcium fraction was abnormal in these cases, though even when it is known to be abnormal isolated calf pain is an unusual symptom. Nevertheless this unscientific therapy may have some effect, since one case appeared to relapse when it was replaced by a placebo.

\section{Fruit and Milk}

Q.-Does the ingestion of milk and citrus fruit together result in the formation of indigestible citrates and malicates of casein which are passed out in the stool, thus depriving the body of the value of both of these foods?

A.-Our knowledge of the interaction between the acids of citrus fruits and milk and other foods is fragmentary. Common obser-

\section{Notes and Comments}

Wasp Repellents.-Dr. T. NORMAN (Winterbourne Houghton, Blandford, Dorset) writes: I was a little surprised at your expert's statement that dimethyl phthalate (D.M.P.) does not harm nylon ("Any Questions?" 5 Septemher p. 622). On the few occasions when I have allowed it to come into contact with nylon the results have been disastrous. I also very much doubt whether it would be the slightest use as a wasp repellent if used on the skin.

My own very considerable experience in the tropics has taught me that while D.M.P. is most effective against the smaller insects it is totally useless against tahanid flies and against flies of the size of bluebottles. It is only iust effective against a horde of really hungry mosquitnes. Even when pure D.M.P. has been really liberally applied the odd mosquito will sit ling enough to bite (but not to take a proper feed). I do not know what the questioner had in mind, but $I$ am quite sure that an angry wasp would sting first and be repelled afterwards.

OUR EXPERT replies: I have contacted the manufacturers of dimethyl phthalate, who confirm my statement that it is extremely unlikely that this substance would have any effect on nylon fabric. To confirm this, I liberally soaked part of an old nylon stocking with undiluted D.M.P. for several hours with no perceptible effect.

The other part of Dr. Norman's comment has more substance. D.M.P. is certainly effective against a wide variety of mosquitoes, sandflies, biting midges, and certain mites. It is appreciably repellent also to houseflies and stable flies. On the other hand, it does appear that it may not be adequately repellent against large insects, and perhaps it was rather rash to guess that it might be effective against wasps.

Protecting the Skin of Incontinent Patients.Dr. G. W. RoBerTs (Mold, Flintshire) writes : I noted with interest the answer given to this question ("Any Questions?" 1 August, p. 296) I have been carrying out clinical trials since 1957 on the use of silicone preparations in the prevention of bedsores, particularly in incontinent patients, and I would not agree with the general statement that silicone creams have no greater value than zinc cream preparations.

Early clinical trials showed that it was necessary for silicone creams to have a $20 \%$ silicone content to be effective. ${ }^{1}$ There are many vation indicates that sour fruit juices can curdle milk, but it seems questionable whether the formation of casein citrates and malicates has any importance in this phenomenon. It is also difficult to see why these compounds, if formed, should be indigestible. Obviously the delicate digestive powers of the infant may react differently from those of the normal adult, and in infant feeding the mixture of milk with fruit juice seems, at the least, inadvisable. An assumption that the infant can necessarily tolerate large amounts of citrus juice by itself, however, may also be unwise, particularly if the juice is sour. In adults the consumption of milk and citrus fruits at the same meal should not unduly strain the digestive system.

With other fruits, such as stewed apples, plums, and damsons, the addition of milk or custard may help to mask some of the sourness in the fruit, and may well be helpful to the digestive processes. The effect of sugar in counteracting sourness and whether sugar affects not only palatability but also digestibility are separate but doubtless related problems.

silicone creams on the market with silicone content of 5 to $10 \%$, and these have not proved effective in the protection of the skin in bedfast patients, particularly incontinent patients. The value of the silicone preparation used will also depend to a large extent on the selection of cases and the technique used in the application of the silicone preparation.

For some years several district nurses in this county have used Conotrane cream, which contains $20 \%$ silicone and phenylmercuric dinaphthylmethane disulphonate (Penotrane). The results have been very satisfactory, ${ }^{2}$ and, applied correctly, I would claim better than zinc cream preparations and less work for the nurses in its application. More recently, a new type of silicone has been introduced-M.S. $555,^{\circ}$ as opposed to M.S. 200 previously used. A silicone aerosol with pure M.S. 555 is also commercially available as Vasogen silicone spray. Used correctly this aerosol will form a tough waterrepellent film on the skin over pressure areas and is valuable in protecting the skin where damage has not already occurred. The silicone aerosol spray is the method of choice in protecting the skin and preventing bedsores in "dry" cases-that is, patients who are not incontinent and with the skin in a non-infected condition. On the other hand, silicone cream is better for incontinent patients and those with early skin damage.

To be effective, silicone preparations must be used correctly and carefully. Using silicone preparations is a new nursing technique and staff must receive full and correct instruction in their use, otherwise failures will be reported and the preparations discarded. I need hardly add that good nursing is of vital importance in protecting the skin of bedfast incontinent patients, regardless of what preparation is used externally.

RFFERENCES

Roberts, G. W., Lancet, 1959, 1, 1207.

Hughes, J. P. W., and Wigley, G. S., Brit. med. f., $1962,2,153$.

Correction.-In the review of the book entitled A Short History of British Psychology 1840-1940 (26 September, p. 807), the author, L. S. Hearnshaw, was inadvertently described as professor of psychology in the University of Bristol instead of the University of Liverpool. 